\title{
THE CHALlENGE OF PROPER GLYCAEMiC CONTROL AMONG PATIENTS WITH TYPE 2 DIABETES IN BANGLADESH
}

\author{
${ }^{1}$ Selim S, ${ }^{2}$ Pathan F, ${ }^{3}$ Saifuddin M, ${ }^{2}$ Latif ZA, ${ }^{4}$ Karim N
}

${ }^{1}$ Department of Endocrinology, Bangabandhu Sheikh Mujib Medical University, Dhaka, Bangladesh, ${ }^{2}$ Department of Endocrinology, BIRDEM General Hospital, Dhaka, Bangladesh, ${ }^{3}$ Feni Sadar Hospital, Feni, Bangladesh, ${ }^{4}$ Department of Epidemiology and Preventive Medicine, Monash University, Melbourne, Australia.

\section{ABSTRACT}

Introduction: Despite the numerous advances achieved in diabetes control and evaluation, the management of this complex disease remains challenging. This study was conducted with the aim of determining the level of glycaemic control among adult patients with type 2 Diabetes mellitus.

Method: The cross-sectional study was conducted in the diabetes care centers of the outpatient departments in Bangladesh. Adult patients with at least 2 years documented history of type 2 diabetes mellitus (T2DM) were recruited and data regarding the demographics, treatment they received and the level of glycaemic control was assessed.

Result: A total of 5140 diabetic patients fulfilling the inclusions criteria were recruited for the study. 9.90\% of the patients were below 40 years of age and the majority $(64.05 \%)$ of the respondents were from urban communities. Based on HbA1c levels, only $18.8 \%$ of the patients had good glycaemic control. Gender, educational level and the income seem to have a relationship with the level of glycaemic control.

Conclusion: Despite the medical advances in the management of diabetes, the glycaemic control of the majority $(81.2 \%)$ of the T2DM patients are still very poor.

Keywords: Type 2 diabetes, glycaemic control, Bangladesh

\section{INTRODUCTION}

According to International Diabetes Federation (IDF), the prevalence of diabetes is expected to rise from 382 million in 2013 to 592 million by 2035 throughout the world and the majority $(80 \%)$ of them will live in low and middle-income countries (1). Diabetes has become the seventh leading burden of diseases in South Asian countries putting an enormous pressure on fragile health systems in low-economic countries (2). In the South Asian region, Bangladesh has the second largest number of adults with diabetes (7.1 million adults, $8.2 \%$ of the adult population) (1). In the year 2010, 3.4 million people died of the consequences diabetes worldwide (3).

The studies have shown that the improved glycemic control in people with diabetes can reduce the risk of long-term complications. The Diabetes Control and Complications Trial (DCCT) and the United Kingdom Prospective Diabetes Study (UKPDS) have provided evidence for the benefits of tight and sustained glycemic control among type 1 and 2 diabetic patients $(4,5)$. All these studies have emphasized the need of maintaining the level of HbA1c of $6.5-7 \%$ for prevention of diabetesrelated complications $(4,5)$. Despite the numerous advances achieved in diagnosis, evaluation and management of this complex disease, achieving proper glycaemic control remains challenging. The epidemiological data suggest that in the majority of patients, the glycaemic control is poor (7-16). Even in the developed countries with strong health care systems, the status of glycaemic control is not very good and only $37.0 \%$ of adults with diabetes had $\mathrm{HbA}_{1 \mathrm{C}}$ levels at the $\mathrm{ADA}$ goal of less than $7.0 \%$ according to the figures in 1999-2000 (16).

A study done in Pakistan in 2007 showed that only $51.4 \%$ of T2DM patients had $\mathrm{HbA}_{1 \mathrm{C}}$ within the control level $(>7 \%)$ and this figure 
was $48.5 \%$ in 2005 (7). Edson et al. found that overall prevalence of inadequate glycemic control in Venezuela was $76 \%$ (8), which was greater than previous estimates from other studies including type 1 and 2 diabetic patients where it is $40 \%$ in Germany (9), 51\% in Denmark (10) and $61 \%$ in Kenya (11). In African Seychelles, less than a quarter of all the patients with diabetes had proper glycaemic control (12) and in a study done by Tel Aviv in Israel, this figure was reported as $41.6 \%$ (12). Studies in India has shown that more than half of the patients with diabetes had poor glycemic control $\left(\mathrm{HbA}_{1 \mathrm{C}}>2 \%\right.$ points above the upper limit of normal and FBG $>139 \mathrm{mg} / \mathrm{dl}$ ) (14).

When the gravity and the cost of diabetes complications are considered, poor glycemic control among patients with diabetes is a concern. The previous study done in 2008 by Latif et al. has demonstrated that the glycaemic control among patients with diabetes in Bangladesh is not that different. This study demonstrated that $76.9 \%$ of the patients failed to achieve the recommended glycaemic target of $<7 \%$ (13). This study was conducted with the objective of gathering information regarding the degree of glycaemic control among adult type 2 diabetic patients with current practice.

\section{METHOD}

This cross-sectional study was conducted among the adult type 2 diabetes at the out-patient departments of Bangladesh and 5 other centres of Bangladesh Diabetes Somity (BADAS) in Dhaka, Bangladesh from January 2013 to December 2013 Ethical approval from the ethical approval committee of BADAS was obtained prior to the commencement of the study. T2DM patients who were having at least 2 years of records were selected to participate the study. The patients who fulfilled the inclusion criteria and who gave written informed consent were recruited. A semi-structured questionnaire containing items. to elicit socio-demographic information and relevant information

about co-morbid illnesses was used. Height, weight, blood pressure

\section{Table 1: Socio demography of the respondents $(n=5140)$}

Frequency $(\%)$

\begin{tabular}{lcc}
\hline Age & & \\
& $<40$ years & $510(9.90)$ \\
& $40-49$ years & $1698(32.99)$ \\
& $50-59$ years & $1724(33.54)$ \\
& 60-69 years & $1066(20.72)$ \\
& $\geq 70$ years & $145(2.83)$ \\
\hline Sex & Male & $2645(51.46)$ \\
\hline & Female & $2495(48.54)$ \\
\hline Residence & Rural & $1848(35.95)$ \\
\hline & Urban & $3292(64.05)$ \\
\hline
\end{tabular}

Table 2: Distribution of the respondents by level of education and occupation $(n=5140)$

Frequency

\begin{tabular}{|c|c|}
\hline \multicolumn{2}{|l|}{ Year of schooling } \\
\hline 5 & 1895 (27.12) \\
\hline $6-12$ & $2954(57.47)$ \\
\hline$\geq 13$ & $291(15.41)$ \\
\hline \multicolumn{2}{|l|}{ Occupation } \\
\hline Student & $16(0.31)$ \\
\hline House wife & $2030(39.49)$ \\
\hline Farmer & $1850(35.41)$ \\
\hline Service holder & $956(18.59)$ \\
\hline Retired & $112(2.19)$ \\
\hline Others & $76(1.48)$ \\
\hline \multicolumn{2}{|l|}{ Habit of smoking } \\
\hline Smoker & $1081(19.09)$ \\
\hline Non-smoker & $3793(73.79)$ \\
\hline Quitted & $266(7.12)$ \\
\hline \multicolumn{2}{|l|}{$\begin{array}{l}\text { Habit of smokeless tobacco } \\
\text { consumption }\end{array}$} \\
\hline Consumer & $1496(29.01)$ \\
\hline Non-consumer & $3392(65.99)$ \\
\hline Quitted & $252(5.00)$ \\
\hline \multicolumn{2}{|l|}{ Habit of alcohol consumption } \\
\hline Consumer & $98(1.9)$ \\
\hline Non-consumer & $5042(98.1)$ \\
\hline Quitted & $08(0.16)$ \\
\hline
\end{tabular}


was recorded. The respondents were requested to fast at least 8 hours and fasting venous blood samples were collected between 7-8 a.m. After 1015 minutes of collection, blood samples were centrifuged for 10-15 minutes at $3000 \mathrm{rpm}$ to obtain serum. Serum $\mathrm{HbA}_{1 \mathrm{C}}$ was measured within a week of sample collection. Collected data were sorted and screened for any discrepancy. The edited data were then entered onto the template of SPSS $^{\circledR} 17$ and STATA ${ }^{\circledR} 12 /$ IC and for decision tree analysis CART $^{\circledR}$ was used.

\section{RESULTS}

The majority of the patients selected patients were between 40 to 60 years of age $(66.53 \%)$, were males $(51.46 \%)$ and were from urban background $(64.05 \%)$. The details of demographic characteristics of the subjects are shown in Table 1. $57.47 \%$ of the subjects have studied up to college level reflecting a considerable level of education among patients with dia-betes in Bangladesh (Table 2). The majority of the females were hou-sewives, which constitute about $43 \%$ of the study population (Table 2). Among the study subjects, around $19 \%$ were smokers, $27.1 \%$ were tobacco consumers, and $1.3 \%$ were alcohol users (Table 2).

About $5 \%$ of the patients were only on medical nutrition therapy (MNT), $43 \%$ of the patients were on oral medication and $52 \%$ of the patients were on insulin therapy in combination with oral medication (Table 3). Irrespective of the duration of diabetes, only about
$18.8 \%$ of the patients had desired glycaemic control (Table 4, 5). The level of glycaemic control was not related the duration of diabetes (Table 5). However, the educational status and the patient's income seem to have relation to the level of glycaemic control and women seem to have a better glycaemic control compared to men (Table 6).

\section{Table 3: Current modalities of treatment for diabetes $(n=5140)$}

\begin{tabular}{lcc}
\hline Current treatment & Frequency (\%) & P value \\
\hline MNT (Medical Nutrition Therapy) alone & $253(4.92)$ & 0.004 \\
MNT + Sensitizer & $569(11.07)$ & \\
MNT + Sensitizer + Secretagogue & $1249(24.29)$ \\
MNT + DPP4 ( Dipeptidyl peptidase-4 inhibitor) & $216(4.20)$ \\
inhibitor & $1093(21.26)$ \\
\hline MNT + Premixed Insulin & $145(2.82)$ \\
\hline MNT + Split mixed Insulin & $436(8.48)$ \\
MNT + Sensitizer + Basal bolus insulin & $931(18.51)$ \\
MNT + Sensitizer + Premixed Insulin & $185(3.59)$ \\
\hline $\begin{array}{l}\text { MNT + Sensitizer + Secretagogue + DPP4 } \\
\text { inhibitor }\end{array}$ & $39(0.79)$ \\
\hline $\begin{array}{l}\text { MNT + Sensitizer + Basal Insulin + GLP1 } \\
\text { (Glucagon-like peptide-1) Analog }\end{array}$ & $21(0.41)$ \\
\hline Others &
\end{tabular}

Table 4: Duration of diabetes and status of diabetes control $(n=5140)$

Duration (Years) HBA1C

\begin{tabular}{lcc}
\hline & Controlled & Uncontrolled \\
$<5$ & $72(18.0)$ & $327(82.0)$ \\
$5-10$ & $75(15.8)$ & $401(84.2)$ \\
$>10$ & $48(17.0)$ & $235(83.0)$ \\
\hline Test statistics & $\chi^{2}=0.7 ; \mathrm{p}=0.61$ & \\
\hline
\end{tabular}

\section{Table 5: Sugar profile of diabetic patients $(n=5140)$}

\begin{tabular}{|c|c|c|c|}
\hline Gender & Diabetes & ontrol status & $\begin{array}{c}\text { HbA1c } \\
\text { Mean }( \pm S D) \%\end{array}$ \\
\hline & Controlled N (\%) & Uncontrolled N (\%) & \\
\hline Male & $472(9.19)$ & $2249(43.75)$ & $9.89 \pm 3.247$ \\
\hline Female & $496(9.69)$ & $2024(56.25)$ & $9.23 \pm 2.741$ \\
\hline Average & \multicolumn{2}{|c|}{18.88} & $9.564 \pm 2.994$ \\
\hline Test statistics & \multicolumn{2}{|c|}{$\chi^{2}=3.1 ; p=0.07$} & \\
\hline
\end{tabular}


Table 6: Distribution of factors, which are associated with HbA1c

$$
\text { OR (95\% CI) }
$$

\begin{tabular}{lll}
\hline Sex & $0.53(0.36,0.77)$ & 0.001 \\
\hline Residence & $0.91(0.58,1.43)$ & 0.678 \\
Education & $0.95(0.91,0.97)$ & 0.002 \\
Income & $1.00(0.99,1.01)$ & 0.183 \\
Duration of DM & $1.01(0.98,1.05)$ & 0.489 \\
\hline Nagelkerke R Square & & 0.059 \\
\hline
\end{tabular}

\section{DISCUSSION}

The patients in Bangladesh has the accessibility to all types of medication including insulin and the modern drugs such as DPP4 inhibitors and GLP1 analogues. Despite the availability of latest management tools and medication for the management of diabetes, only about $18 \%$ of the T2DM patients in Bangladesh had desired glycaemic control (HbA1C $\geq 7 \%$ ). Patient's gender, educational status and the patient's income seem to have an association with the levels of glycaemic control.

The benefits of tight glycaemic control are well known (5). Despite of clear evidence, many patients fails to reach an optimal glycemic target $(17,18)$. Even with the medical advances and availability of modern drugs and health care fascilites, managing diabetes has been a challenge throughout the world. It has been even more difficult in developing countries and almost similar findings have been reported in Bangladesh in previous studies (15). In neighboring India, the situation is little better than Bangladesh and Raheja et al. showed that more than half of the diabetic patients in India had poor glycemic control (16). Even in countries with highly educated people with strong health care systems, the level of glycemic control is not that different and in the USA, only $37.0 \%$ of adults had HbA1c levels at the ADA goal of less than $7.0 \%$ (19).

In a given community, various factors could influence the level of glycaemic control in patients with diabetes. Gender of the patient seems to have a significant relationship with the levels glycaemic control. A Finish study has demonstrated that male patients had better glycemic control than female patients (18). Apart from socioeconomic factors such as educational level and financial status, inadequate knowledge about diabetes has been reported to negatively affect behavior and self-care among diabetes patients (20). In contrast to the Finish study, the level of glycaemic control is better in females compared to males. The glycaemic control among educated and among patients with a higher income has been better. This probably could be due to the better accessibility and availability of health care for these categories of patients. According to available data, the majority diabetic patients do not receive sufficient diabetes education (21) and this probably in the main reason for the poor glycaemic control among patients with diabetes. These findings highlight the importance of the quality of the diabetes care and importance of diabetes education provided to these patients.

\section{CONCLUSIONS}

Despite the availability and having the accessibility of modern health care fascilities and drugs, glycaemic diabetes in Bangladesh. Although the women and the patients with a better education and income had slightly control is poor among patients with better glycaemic control, proper glycaemic control has been a challenge and has been a universal problem.

\section{ACKNOWLEDGEMENT}

The authors are grateful to the Ministry of Health \& Family Welfare of Bangladesh for the financial support and also the respondents of the study.

\section{REFERENCES}

1. Guariguata L, Whiting DR, Hambleton I, Beagley J, Linnenkamp U, Shaw J. Global estimates of diabetes prevalence for 2013 and projections for 2035, IDF Diabetes Atlas 2013. Diabetes Research and Clinical Practice. 4014; 103: 137-149.

2. Mohan V, Seedat Y, Pradeepa R. The Rising Burden of Diabetes and Hypertension in Southeast Asian and African Reagons. Need for Effective Strategies for Pre-vention and Control in Primary Health Care Settings. Inter-national Journal of Hyper-tension. 2013; 14 pages.

3. World Health Organization. Definition, Diagnosis and Classification of Diabetes Mellitus and its complications. Report of a WHO Consultation, Part1: Diagnosis and Classification of Diabetes Mellitus. WHO, Geneva. 2013.

4. Diabetes Control and Complications Trial Research Group. The effect of intensive tre-atment of diabetes on the development and progression of long-term complications in insulin-dependent diabetes me-llitus. New England Journal of Medicine. 1993; 12: 977986.

5. UK Prospective Diabetes Study (UKPDS) Group. Inte-nsive blood-glucose control with sulphonylureas or insulin compared with conventional treatment and risk of comp-lications in patients with type 2 diabetes (UKPDS 33). The Lancet. 2002; 352: 837-853.

6. American Diabetes Association 2012. Classification and diag-nosis of diabetes mellitus. Diabetes Care. 2012; 34(1): 2-7.

7. Khan DA, Saeed M, Khan FA. 
Is Glycemic control improving diabetic patients with type 2 diabetes in Rawalpindi? Journal of Ayub Medical College Abbottabad. 2012; 21(1): 62-65.

8. Moreira ED, Neves RCS, Nunes ZO, de Almeida MCC, Mendes ABV, Fittipaldi JAS et al. Glycemic control and its correlates in patients with diabetes in Venezuela: Diabetic Research and Clinical Practice. 2010; 87: 407-414.

9. Pittrow D, Stalla GK, Zeiher AM, Silber S, Marz W, Pieper L et al. Prevalence, drug treatment and metabolic control of diabetes mellitus in primary care. Mediziniche Klinic. (Munich). 2007; 10: 635-644.

10. David BS. Correlation between Hemoglobin A1c (HbA1c) and average blood glucose: Can HbA1c be reported as estimated blood glucose concentration? Journal of Diabetes Science and Technology. 2007; 1(6): 801803.

11. Otieno CF, Marikuri M, Ng'anga L. Quality of glycemic control in ambu-latory diabetics at the out-patients clinic of Kenyatta National Hospital, Nairobi. East African Medical Journal. 2003; 80: 406-410.

12. Faeh D, William J, Tappy L, Ravussin E. Prevalence, awareness and control of diabetes in the Seychelles and relationship with excess body weight. BioMed Central Public Health. 2007; 7: 163.

13. Michal S, Tomas RT, Shlomo V, Alexander L, Rina E, Asher E et al. Charac-teristics of Diabetics with Poor Glycemic Control Who Achieve Good Control. Journal of the American Board of Family Medicine. 2007; 21: 113-119.

14. Raheja BS, Kapur A, Bhoraskar A, Sathe SR, Jorgensen LN, Moorthi SR et al. Dia-bCare Asia-India study: diabetes care in India-current status. Journal of Associations of Physicians of India. 2001; 49: 717-722.

15. Latif ZA, Jain A, Rahman MM. Evaluation of mana-gement, control, complicat-ions and psychosocial asp-ects of diabetics in Bangladesh: DiabCare Bang-ladesh 2008. Bangladesh Medical Research Council Bulletin. 2011; 37: 11-16.
16. Saydah SH, Fradkin J, Cowie CC. Poor control of risk factors for vascular disease among adults with previously diagnosed diabetes. Journal of American Medical Association. 2004; 291: 335-342.

17. Chuang LM, Tsai ST, Huang BY, Tai TY. Diabcare-Asia 1998 Study Group. The status of diabetes control in Asia - a cross-sectional surv-ey of 24 317 patients with diabetes mellitus in 1998. Diabetic Medicine. 2002; 19: 978-985.

18. Namasivaym KG, Rajase-karan $M$, Sivagnanam G, Thirumalaikolundusubram-anian $\mathrm{P}$, Ravindranath C. A comparative study of the knowledge, beliefs and practices of diabetic patients cared for at a teaching hospital (free service) and those cared for by private practitioners (paid service). Annals of the New York Academy of Sciences. 2002; 958: 416-419.

19. Van der Does FE, De Neeling JN, Snoek FJ, Kostense PJ, Grootenhuis PA, Bouter LM et al. Symptoms and well-being in relation to glycemic control in type II diabetes. Diabetes Care.1996; 19: 204-210.

20. Rafique G, Azam S1, White F. Diabetes knowledge, benefits and practices among people with diabetes attending a university hospital in Karachi, Pakistan. East Mediterr Health Journal. 2006; 12: 590-598. 